\title{
UNICEF, infância, educação e práticas de proteção de direitos no
}

Brasil

\author{
UNICEF, children, education and practice of rights protection in
}

Brazil

http://dx.doi.org/10.5007/2178-4582.2017v51n2p388

\begin{abstract}
Flávia Cristina Silveira Lemos, Nathália Dourado Frazão Costa, Rafaele Habib Souza Aquime, Leandro Passarinho e Mariane Bittencourt

Universidade Federal do Pará, Belém/PA, Brasil
\end{abstract}

\begin{abstract}
Esse artigo traz uma análise de práticas do Fundo das Nações Unidas para a Infância (UNICEF) sobre a educação infantil e a produção do objeto infância, no Brasil, a partir da Constituição de 1988. Resulta de pesquisa de mestrado na área de educação e psicologia escolar, com contribuições históricas e documentais. Aponta rupturas e descreve práticas na política da educação infantil brasileira escolar, a partir da Lei das Diretrizes e Bases da Educação, de 1996. Busca articular as relações entre as propostas do UNICEF, a LDB1996 e o Estatuto da Criança e do Adolescente de 1990, no panorama do cuidado e da educação de crianças pequenas e os efeitos dessas relações estabelecidas no governo dos corpos para a produção da infância escolar.
\end{abstract}

Palavras-chave: Educação Infantil; Governo das condutas; Políticas Públicas; UNICEF; Brasil.
This article presents an analysis of the United Nations Fund practices for Children (UNICEF) on child education and the production of child object, in Brazil, from the Constitution of 1988. It follows from master's research in the area of education and psychology school, with historical and documentary contributions. Points breaks and describes practices the politics of Brazilian school children education, from the Law of Education Guidelines and Bases, 1996. Search articulate the relationship between the proposals of UNICEF, the LDB-1996 and the Statute of Children and Adolescents 1990 in the panorama of care and early childhood education and the effects of these relationships established government bodies to the school production childhood.

Keywords: Early Childhood Education; Government of pipelines; Public Policy; UNICEF; Brazil.

\section{Introdução}

Diante da extensa produção documental do Fundo das Nações Unidas para Infância (UNICEF) acerca da infância e políticas para a educação de crianças em geral, surgiu o interesse em debruçar-se sobre tal produção discursiva para poder vislumbrar um panorama histórico da educação infantil brasileira focalizando as práticas do UNICEF enquanto organismo multilateral para a formulação de políticas para educação infantil, e consequentemente os efeitos produzidos para o delineamento de uma noção de infância e de educação infantil, especialmente para países em desenvolvimento.

Com a nova Lei de Diretrizes e Bases (LDB) (1996) a educação infantil passou a ser considerada primeira etapa da educação básica e a ela foi atribuída uma finalidade de promover "o desenvolvimento integral da criança até seis anos de idade, em seus aspectos físico, psicológico, intelectual e social, 
complementando a ação da família e da comunidade", com a instituição do FUNDEB, que está em vigor desde 2007, a educação infantil também passou a poder receber recursos do governo federal que antes eram apenas destinados para o ensino fundamental, que segundo o UNICEF era a prioridade número um dos países em desenvolvimento.

Tais mudanças no cenário educacional brasileiro são, é claro, uma luta de forças, produção de poderes, agenciamento de saberes, resultado de reinvindicações sociais e demandas internacionais de organismos como a ONU (UNICEF e UNESCO). E é partindo de tal cenário de mudanças, lutas de forças e agenciamento de redes em relação à educação de crianças de 0 a 6 anos que abro um parêntese para fazer um esclarecimento. Penso que um leitor mais atento e conhecedor das normativas que transitam no campo da legislação brasileira tenha se perguntado: Porque o presente estudo se ocupa de uma abordagem histórica da educação infantil brasileira para crianças de 0 a 6 anos, no período de 1996 a 2012, se existem normativas que determinam a matricula obrigatória de crianças aos 06 anos no $1^{\circ}$ ano do ensino fundamental (Lei $11.114 / 2005$ ), bem como outras determinações como a emenda constitucional $n^{\circ} 53$ de 2006 que modifica os artigos $7^{\circ}$ e 208 da Constituição, bem como da LDB e determinam que a educação infantil se dará dos 0 aos 5 anos?

A resposta é que por opção metodológica decidiu-se manter a faixa etária de 0 a 6 anos devido ao seu uso ainda corrente em diferentes referências utilizadas neste trabalho, assim como destacar seu caráter recente, a partir de 2005. Outro fato importante é que tal detalhe da antecipação do ingresso no ensino fundamental também pode ser uma das pautas de pesquisa, tendo em vista que a justificativa desta pesquisa será a de possibilitar que se problematizem questões que estão postas como naturais, como a noção de infância e de educação infantil, a livre intervenção técnica de organismos multilaterais em assuntos de educação de crianças desfavorecidas, e o uso do direito para tornar direitos adquiridos em objetos de obrigatoriedade e de sanções.

Para a análise desses documentos, que serão escolhidos por critério de pertinência ao objeto de estudo aqui posto, serão destacados e analisados enunciados discursivos acerca da noção de infância e de educação infantil, almejando justamente traçar um mapa de como se deu a produção do objeto infância pelas práticas/relatórios do UNICEF, procurando evidenciar quais estratégias de saber e tecnologias de poder foram acionadas e operacionalizadas para a referida produção de uma noção de infância e educação infantil. O fazer genealógico opera descartando, enfim, o objeto tido por natural e destacando o jogo de casualidades que forjaram tais objetos, como por exemplo, a infância de direitos e a educação infantil. Veyne (1998, p. 254) nos dá uma interessante contribuição. 
Reconhecer, enquanto genealogista, o objeto como nada mais sendo do que um efeito de diversas racionalizações nos faz chegar à conclusão que o objeto nada mais é do que um fruto de nossas racionalizações em diferentes épocas e que, na verdade, o que existe seria um universo material com elementos prédiscursivos que sofrem com as implicações de diferentes práticas que atuam sobre tais objetos. Para fechar tal ideia, vale destacar aqui que o objeto da presente pesquisa são as práticas de governamentalidade do UNICEF que são objetivadas como governo da infância, de forma que estudar tais práticas me possibilitaram interrogar como foram constituídas as práticas de objetivação da infância de forma que o objeto feito também forja seu correlato, produzindo encomendas e políticas específicas imanentes em uma rede de práticas vizinhas que operam conjuntamente com o UNICEF, no Brasil.

Estas práticas emergem em um campo da educação nomeada como infantil, norteado por um ideal específico, em todo seu aparato discursivo e não discursivo pautado em saberes heterogêneos e poderes estratégicos, articulados às leis e táticas diversas. Vale então ressaltar que se "O objeto não é senão correlato da prática.” (VEYNE, 1998, p. 250). Portanto, a produção discursiva do UNICEF é histórica não apenas no sentido tempo/acontecimento/ cronologia, mas também a partir do momento em que veicula verdades sobre a infância, e promove lutas para que tal verdade seja tida não apenas como uma causa sua, mas sim como uma causa em que toda a sociedade deveria se engajar, promovendo o jargão "todos pelas crianças". Logo, a discussão acerca da verdade enquanto instância almejada por discursos como o do UNICEF está relacionada com a vontade de saber e a vontade (histórica) da verdade. A vontade da verdade enquanto aspiração de discursos científicos trata-se de uma maquinaria excludente permeada pela arbitrariedade, acaso, desejo e poder, em que a verdade é estabelecida entre técnicas de saber e estratégias de poder (em que há uma ordem do discurso). Logo, podemos lançar os seguintes questionamentos com relação às práticas de organismos como o UNICEF, como por exemplo: Tal objetivação da infância não seria em prol de uma dada subjetivação almejada pelos gestores da ordem e desenvolvimento? Qual a ambição do UNICEF de ter seus discursos como portadores de verdade acerca da infância, que ambição de poder se manifesta em tal desejo? Se a verdade é produzida graças a múltiplas coerções e produz efeitos de poder, qual o papel econômico- político que o estatuto de verdade almejado pelos discursos do UNICEF visa desempenhar?

Para tentar responder tais perguntas, a genealogia de Foucault foi uma escolha que se deu com o intuito de desnaturalizar os discursos sobre a infância e educação infantil produzido pelo UNICEF. Esse organismo multilateral internacional tomou para si a responsabilidade de ser porta-voz de 
assuntos de relevância social em nível mundial, além disso, ao amparar suas produções documentais em saberes do direito, da medicina, da psicologia do desenvolvimento infantil, etc. foi coroado (cabe saber por quem) com uma legitimidade política e científica para emitir pareceres e relatórios, e embasado em tal relação de saber-poder que lhe caracteriza, fez com que suas contribuições teóricas a partir de seus estudos sobre a situação da infância, qualidade da educação, saúde e condições de famílias pobres, se tornassem cada vez mais decisivas na elaboração e implantação de políticas públicas, inclusive políticas educacionais. Mas, que aportes discursivos sustentam as práticas do UNICEF e norteiam suas perspectivas para a infância e adolescentes, e a família desfavorecida em geral? Que relações de poder são engendradas por tal discurso que se responsabiliza por forjar cidadãos e a garantia de seus direitos para que alcancemos uma sociedade justa e de equidade social?

Portanto, o problema em questão trata-se de desnaturalizar discursos que se dizem em prol do bem estar social e da melhoria de vida. Para isso a análise da História estará a nosso dispor para que venhamos a desbravar discursos e seus contextos geradores, além de problematizar as relações de poder contemporâneas, o ideário neoliberal, governamentalidade e suas implicações nos discursos sobre a infância e a educação. A tríade saber-poder-corpo é plenamente passível de ser analisada nos discursos do UNICEF, tendo em vista que suas práticas visam agir diretamente nos corpos infantis em prol de seu pleno desenvolvimento, com as melhores condições familiares possíveis, com o afeto e proteção que devem ser presentes na vida de cada criança, segundo o UNICEF.

Ou seja, estudar a infância e propostas de educação infantil nesta presente pesquisa não será verificar como a partir de diferentes manifestações sucessivas que incidiram sobre estes dois objetos, estaríamos quase alcançando aquilo que sempre teria sido, ainda que no princípio, não tivéssemos definido a intenção primordial de zelar e produzir uma infância protegida. Mas afinal, em que tipo de procedimento metodológico consiste o genealógico? Seria uma abordagem que implica em se procurar fazer uma história do presente através de desnaturalizações de fatos históricos, práticas e discursos diversos não apenas pelo simples fato de desnudar essa realidade, mas combatendo os efeitos de poder que tais naturalizações em geral fazer circular.

\section{Década de 70 e 80: atuação do UNICEF e programas nacionais para EI}

O UNICEF apresentou um importante papel para a constituição de uma proposta de educação para crianças de 0 a 6 anos, segundo Maria Lucas (2009), em artigo intitulado "A influência do UNICEF e da UNESCO na educação infantil brasileira contemporânea" que discute a respeito das 
funções conferidas à educação infantil brasileira entre o final da década de 1970 e final de 1980, tais organismos multilaterais contribuíram para que no Brasil houvesse uma cisão entre as tendências assistencialista e a tendência educacional. Entretanto, apesar dessa dita cisão entre essas duas tendências, estudos históricos apontam para a prevalência de iniciativas informais e assistencialistas tidas como alternativa viável para a democratização da educação infantil (KRAMER, 2006). No final da década de 70, exatamente no ano de 1977, foi lançado o primeiro programa brasileiro de educação infantil, o chamado Projeto Casulo e que foi desenvolvido pela Legião Brasileira de Assistência (LBA), esta legião foi criada em 1942 e se destacou por obras assistenciais brasileiras até que em 1966 foi transformada em Fundação e passou a ter por finalidade "prestar assistência à maternidade, a infância e a adolescência" (KRAMER, 1995, p. 72).

Segundo Kramer (1995) este projeto visava atender o maior número possível de crianças a baixo custo, prestando assistência a crianças de 0 a 6 anos com o intuito de prevenir a marginalidade. Além disso, a autora destaca que o projeto firmava convênios com prefeituras, Estados ou ainda com a iniciativa privada e que o repasse de verbas se restringia a alimentação, material didático, equipamentos, entre outras coisas, sendo que o pagamento de pessoal ficava a cargo da instituição conveniada, fato que ocasionou na situação que ora se instalou do funcionamento de instituições de educação infantil com pessoas sem remuneração devida, ou voluntariado.

Podemos perceber que tal projeto foi desenvolvido durante o período militar e Rosemberg destaca que justamente neste período o UNICEF previa algumas indicações de educação para países subdesenvolvidos, e que o Projeto Casulo nada mais foi do que a concretude de discursos inerentes ao UNICEF, ao contexto da Guerra Fria e da ditadura militar no Brasil. Vejamos por parte tais afirmações. A ditadura militar veiculava o discurso da Doutrina da Segurança Nacional (DSN), tal concepção apregoava a pobreza como ameaça a segurança nacional, associado a esse discurso o regime militar valeuse da teoria e da prática do Desenvolvimento de comunidade (DC), ambos preconizavam que as políticas de assistência se fizessem valer da estratégia da participação da comunidade para implantação de políticas sociais. Tal estratégia era incentivada por organismos multilaterais como o UNICEF, Rosemberg (2002, p. 36) nos traz uma definição simples do DC: "Em 1956, a ONU definia o DC como o processo através do qual os esforços do próprio povo se unem aos das autoridades governamentais com o fim de melhorar as condições econômicas, sociais e culturais da comunidade (...)".

Parte deste discurso se faz perceptível nos documentos do UNICEF neste período, Rosemberg (2002) destaca que após o estudo de alguns documentos do 
UNICEF e UNESCO foi possível sistematizar alguns argumentos, princípios e propostas de modelo de EI para os países subdesenvolvidos propostos por essas duas agências, entre eles os de que a "expansão da EI constituía uma via para combater a pobreza; indicações de que a forma de expandir a EI nos países subdesenvolvidos deveria se dá por meio de modelos que minimizem investimentos públicos, logo, tais programas deveriam se apoiar nos recursos da comunidade, sob a forma de programas 'não formais', 'alternativos", 'não institucionais'."

Tal configuração social, política e econômica além das influências diretas de discursos de âmbito internacional repercutiram nas formulações para uma política de educação infantil no período de 1970 e 1980. O que é possível perceber é que, do aspecto da forma, a educação pré-escolar no Brasil, e que foi incentivada pelo UNICEF na década de 1970 e 1980, prevalecia o caráter compensatório nas ações desenvolvidas, com relação a isso Rosemberg (2002).

Pontua que sob a lógica das organizações multilaterais para a educação infantil foi destinado um parco investimento público, com professores leigos mal remunerados e espaços improvisados não só em termos de estrutura física como também de materiais pedagógicos, de modo que o quadro que se instalou foi o de que Rosemberg (2002) faz uma interessante colocação acerca da educação infantil que ora se instalava no Brasil e a educação primária até então vigente, de que esta era de baixa qualidade, com altos índices de repetência, e de metodologias centradas no professor e que "A este arsenal, acrescentouse a sucata." (p. 38), se referindo as condições de implantação da educação infantil no país. Por fim, todas as críticas desferidas a tal cenário acabaram por incentivar debates e discussões acerca do que se almejava para a educação infantil brasileira. Pois "Apesar dos equívocos das propostas educacionais compensatórias, elas tiveram na década de 1970 o papel de impulsionar o debate sobre as funções e currículos da pré-escola, legitimando a educação pré-escolar, relacionando pré-escola e escola de $1^{\circ}$ grau" (KRAMER, 2006, p. 801).

\section{Entrada do BM no financiamento da educação infantil na década de 90}

Em decorrência de demandas sociais foi formulada em 1993 uma Política Nacional de Educação Infantil que primava pelo afastamento do modelo "não formal" que predominava no Brasil e se contrapunha ao modelo de baixo investimento para a educação infantil até então tido como natural, entretanto, tal processo sofreu um corte, uma descontinuidade com a gestão federal de Fernando Henrique Cardoso que viabilizou uma reforma educacional pautada em orientações economicistas bem como nas recomendações do Banco 
Mundial (BM). Neste período, o BM estabeleceu que o ensino fundamental fosse uma etapa da educação onde deveriam se concentrar os recursos públicos devido a suas taxas maiores de retorno de investimento do que em outras etapas da educação. Logo, a entrada do Banco Mundial na década de 1990 no financiamento da educação brasileira acabou por transformar a ideia de prioridade do investimento no ensino fundamental em uma exclusividade, o que acarretou em uma estagnação na EI (ROSEMBERG, 2002).

Logo, o que é possível perceber é que do aspecto da forma tal influência do BM acarretou em uma retomada dos moldes compensatórios. Além disso, suas ações desenvolvidas se davam com direcionamento para dois tipos de financiamento sendo que o primeiro era de caráter pré-escolar, associado à melhoria do desempenho das crianças no ensino fundamental; e também a linha do Desenvolvimento Infantil (DI) que considerava tanto ampliações que englobem saúde, nutrição e educação, como também modelos não formais de atendimento a crianças pequenas. (ROSEMBERG, 2002). Vemos que aqui se instala uma descontinuidade que se contrapunha as demandas sociais. Condições políticas, econômicas assim como efeitos da globalização e do neoliberalismo se fizeram sentir no rumo que se dava nas políticas de EI, e os apontamentos dados pela Política Nacional de 1993 com brevidade foram desconsiderados a partir da retomada de propostas de educação compensatória para as classes desfavorecidas, pois a priorização do ensino fundamental acabou tornando-se uma exclusividade de investimentos.

Tal cenário pode ser materializado na criação do Fundo de Manutenção e Desenvolvimento do Ensino Fundamental e de Valorização do Magistério (FUNDEF/ Lei $\mathrm{n}^{\circ} 9424$ de 24 de dezembro de 1996) que discorre que a distribuição dos recursos se daria na proporção do número de alunos matriculados nas $1^{\mathrm{a}} \mathrm{a} 8^{\mathrm{a}}$ séries do ensino fundamental, bem como o que preconiza o Art. $2^{\circ}$ que diz "Os recursos do Fundo serão aplicados na manutenção e desenvolvimento do ensino fundamental público, e na valorização de seu Magistério." (BRASIL, 1996).

\section{Marcos legais para a educação infantil brasileira: Constituição de 1988, Estatuto da Criança e do Adolescente de 1990 e a LDB de 1996}

A Constituição de 1988 e seu caráter decisivo para a entrada da educação infantil no rol dos direitos sociais e também da educação. Até então a EI estava associada aos campos da assistência, fato que a tornava de caráter assistencialista e compensatória e destinada sempre a um público específico, que eram as famílias mais desfavorecidas (KUHLMANN JUNIOR, 1998). A partir do momento em que a educação é trazida na nossa Constituição de 1988 
como um direito de todos e dever do Estado, e a educação infantil figurando no artigo 208 que trata "Da educação, da cultura e do desporto", torna-se visível o salto de sua condição até então esquecida e apartada do contexto educacional para outro plano que a inclui no campo da educação brasileira, e equiparada às outras etapas da educação como sendo um direito de todos e dever do Estado. Na introdução do documento que trata da Política Nacional de Educação Infantil (2006) o reconhecimento da Constituição de 1988 como um marco legal também se faz presente.

Todas essas especificações mais detalhadas são de fato significantes para a Educação infantil, pois, segundo Rosemberg (2003, p. 51) "Assim, pela primeira vez, o Estado brasileiro reconheceu que o direito a educação se inicia antes do ensino fundamental, nomeia e situa a creche, instituição que vinha sendo colocada a margem de qualquer regulamentação". Vejamos então os dois momentos em que a educação infantil é citada na Constituição de 1988. No artigo 7, intitulado 'Dos direitos Sociais" em que a educação aparece em primeiro lugar enquanto direito social, juntamente com outros direitos como a proteção a infância, a saúde, trabalho, lazer, etc., a educação infantil propriamente dita, é prevista no inciso XXV que diz da "assistência gratuita aos filhos e dependentes desde o nascimento até seis anos de idade em creches e pré-escolas"(BRASIL, 1988, art. 7) enquanto direito dos trabalhadores urbanos e rurais, estando atrelada a outras condições que visem à melhoria da condição social desses trabalhadores.

Vemos que neste primeiro momento a EI esteve associada ao direito do trabalhador de ter assistência aos seus filhos devido à sua condição de trabalhador, entretanto, ainda que a priori o direito da criança apareça como estando condicionado a outras pessoas que não ela mesma, ainda assim tal passo dado pela Constituição é um avanço do ponto de vista do reconhecimento da necessidade de atendimento que essa criança demandaria em outro ambiente que não fosse sua residência. Outro artigo da constituição que contorna tal situação no que diz respeito à infância e seus direitos específicos é o artigo 208 que trata "Da educação, da cultura e do desporto", nele a educação enquanto dever do Estado será efetivada, no que diz respeito à educação infantil, mediante a garantia do previsto no inciso IV: "atendimento em creche e préescola às crianças de zero a seis anos de idade" "(BRASIL, 1988, art.208). É importante observar que é apenas a partir deste artigo que realmente a educação infantil passa a integrar o campo educacional brasileiro, pois sua condição aqui extrapola o direito social das crianças na condição de filhos ou dependentes para adentrar em uma área de competência e de compromisso do Estado, enquanto o dever na garantia de atendimento destas crianças em estabelecimentos de Educação Infantil. 
A partir daqui pode-se vislumbrar para a EI um horizonte mais completo que trata não só da guarda dessas crianças de 0 a 6 anos, mas também da educação das mesmas, para Campos et al. (1995) tal fato representa um avanço bastante significativo no que diz respeito a criação de uma realidade mais favorável ao desenvolvimento integral da criança brasileira. Ao considerar neste trabalho a Constituição de 1988 como um dos primeiros marcos legais para a educação infantil brasileira, podemos destacar não apenas o reconhecimento do direito ao atendimento em creches e pré-escolas de crianças de 0 a 6 anos como um fruto do movimento constituinte e de outras forças provindas dos movimentos sociais diversos, mas, também a importante indicação pela primeira vez na história brasileira de que tal nível de atendimento deveria estar subordinado ao sistema educacional.

Ainda que em outros momentos tal caráter educacional deste atendimento já houvesse sido indicado no decorrer da história da educação infantil brasileira, nas décadas de 70 e 80 , com a cisão entre as tendências assistencialista e a tendência educacional para a educação infantil (ROSEMBERG, 2002), foi apenas com a carta magna de 1988 que tal pressuposto se oficializou mediante a regulamentação legal que foi posta. Outro marco na legislação brasileira no que diz respeito à infância e a educação infantil é o Estatuto da Criança e do Adolescente (ECA) de 1990, que trata sobre a proteção integral à criança e ao adolescente, equipara a criança e o adolescente a outros cidadãos no que diz respeito aos direitos fundamentais inerentes à pessoa humana, além de lhes assegurar oportunidades e facilidades que venham lhes proporcionar o desenvolvimento físico, mental, moral, espiritual e social, em condições de liberdade e de dignidade (BRASIL, 1990, art. 3).

No artigo 4, a família, a comunidade, a sociedade em geral assim como o Poder Público são chamados a assegurar, com absoluta prioridade, a efetivação dos direitos referentes a vários aspectos da vida das crianças e adolescentes, inclusive do direito a educação. Mas apenas no artigo 54 no inciso IV é que o dever do Estado em assegurar à criança o direito a EI figura ratificando o já previsto na Constituição e que consiste no "atendimento em creche e préescola às crianças de zero a seis anos de idade" (BRASIL, 1990, art. 54).

A Lei de Diretrizes e Bases da Educação finaliza uma importante fase para a consolidação inicial da Educação Infantil no cenário da legislação brasileira, foi neste momento em que efetivamente foi mencionada como a primeira etapa da educação básica (art. $21^{\circ}$ ) e tendo “(...) como finalidade o desenvolvimento integral da criança até seis anos de idade, em seus aspectos físico, psicológico, intelectual e social, complementando a ação da família e da comunidade." (BRASIL, 1996, art. 29º). 
Foi a partir da LDB que se deu um processo de descentralização e municipalização da educação infantil ficando sob responsabilidade dos municípios que passaram a ter por responsabilidade "oferecer a educação infantil em creches e pré-escolas, e, com prioridade, o ensino Fundamental."

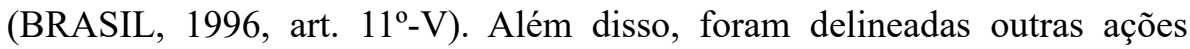
acerca da formação de docentes para a educação infantil e da responsabilidade dos institutos superiores de educação na formação dos mesmos. A partir de então, a educação infantil, que tinha como agentes de educação pessoas com pouquíssima ou sem qualificação pedagógica passou a ter para si outros caminhos, pelos menos no campo da legislação, no que diz respeito às pessoas que deveriam atuar nessa etapa da educação básica.

Tal preocupação de âmbito federal demonstrou-se um avanço e um alvo a ser perseguido para a melhoria do atendimento prestado nas instituições de educação infantil, e que passasse a primar não apenas pela democratização do atendimento, mas também pela sua qualidade. Entretanto, apesar de todo esse aspecto operacional que descrevia finalidades, competências dos entes federados e das instituições de nível superior e suas responsabilidades para com a educação infantil, as dotações orçamentárias para a educação infantil não foram suficientemente delimitadas, por isso se faz necessário destacar que o avanço ocasionado pela LDB deu-se na verdade em detrimento do provimento de recursos específicos para educação infantil (ROSEMBERG, 2003). Podemos concluir que apesar de algumas limitações e das lacunas deixadas para a educação infantil brasileira, o avanço foi inegável. Houve trouxe precedentes para uma valorização da educação infantil pela esfera governamental e um crescente compromisso pela regulamentação dessa etapa da educação básica, além disso, tais formulações acabaram por promover uma mudança do sentido conferido à educação infantil e o caminhar em direção à superação do caráter preconceituoso que permeava tal etapa da educação.

\section{Educação infantil pós LDB: mudanças no cenário para uma política nacional de educação infantil.}

Até que a Constituição de 1988 e a LDB de 1996 destacassem o local da educação infantil no cenário educacional brasileiro, dos direitos sociais e dos direitos da criança e do adolescente muitos foram os embates para uma objetivação do que seria uma educação para a infância, especialmente das crianças de 0 a 6 anos. A partir de uma leitura de Kramer (1995) podemos constatar que antecedentes na legislação denotam que apesar de na Lei no 5692 , de 1971, dispor que "os sistemas de ensino velarão para que as crianças de idade inferior a sete anos recebam conveniente educação em escolas maternais, 
jardins de infância e instituições equivalentes", e que em 1975 o Ministério da Educação e Cultura tivesse instituído a Coordenação de Educação PréEscolar, tal cenário se arrastou ainda indeterminado. Entretanto, ainda assim muitos foram os programas desenvolvidos no Brasil, com variados contornos e concepções para o atendimento as crianças de 0 a 6 anos.

De modo que reconhecer a LDB teve um impacto na EI é indiscutível do ponto de vista da lei, pois se até então o Estado era omisso, a partir deste momento fica explícito seu dever e o direito a educação básica, sendo a educação infantil sua primeira etapa. Segundo Rosemberg (2003), além do impacto da LDB no sentido da EI ter sido integrada no sistema de ensino e da especificação que esta deveria ser de responsabilidade municipal. Vejamos alguns desdobramentos da LDB para a educação infantil por ordem cronológica. Primeiramente podemos citar o documento elaborado sob a coordenação do MEC intitulado Subsídios para credenciamento e funcionamento de instituições de educação infantil (1998), que teria contribuído "significativamente para a formulação de diretrizes e normas para a Educação Infantil no Brasil” (BRASIL, 2006, p. 11).

No mesmo ano foi elaborado o Referencial Curricular Nacional para a Educação Infantil (1998) que consiste num conjunto de referências e orientações pedagógicas para direcionar a ação dos docentes de educação infantil, entretanto o documento, que é composto de três volumes, não deve ser tomado como base obrigatória, mas sim como uma base referencial (BRASIL, 2006, p. 13) Nele figuram discussões sobre o professor de educação infantil, os objetivos gerais da educação infantil, assim como algumas considerações sobre a instituição de educação infantil e o projeto educativo. Em 1999 o Conselho Nacional de Educação definiu a primeira versão das Diretrizes Curriculares Nacionais para a Educação Infantil, que conta com sua versão mais recente do ano de 2010. A versão mais recente das Diretrizes Curriculares Nacionais para a Educação Infantil decorre do que foi previsto na Resolução $\mathrm{n}^{\mathrm{o}}$ 5, de 17 de dezembro de 2009. As Diretrizes Curriculares Nacionais para a Educação Infantil (2010) discorrem sobre os objetivos, definições e concepção da Educação Infantil. Os princípios, assim como os objetivos da proposta pedagógica também estão presentes no documento. Outros aspectos figuram tais diretrizes como a organização de espaço, tempo e materiais, as práticas pedagógicas da educação infantil, algumas considerações sobre a avaliação, e a articulação da EI com o Ensino Fundamental.

No que diz respeito à proposta pedagógica, esta é tratada a partir de segmentos diversos aliando proposta pedagógica e diversidade, proposta pedagógica e crianças indígenas, e as infâncias do campo. Em 2001 o Plano Nacional de Educação traz um capítulo sobre a Educação Infantil, assim 
como determina que os estados, Distrito Federal e municípios elaborem planos decenais para a educação. No que diz respeito à EI, pode-se concordar com a afirmação de que "A Educação Infantil, constituindo um capítulo desses planos, tem seu horizonte de expansão e melhoria definido como obrigação dos sistemas de ensino da União, dos estados, do Distrito Federal e dos municípios" (BRASIL, 2006, p. 16).

Em 2005 foi lançado o Programa de Formação Inicial para Professores em Exercício na Educação Infantil (PROINFANTIL) que consiste em uma iniciativa do MEC que disponibiliza na forma de curso a distância em nível médio e na modalidade Normal, um programa de formação de professores de Educação Infantil que atuam em creches e pré-escolas e que não possuem a formação exigida pela legislação. Apesar de todas essas medidas citadas anteriormente que acabaram por acenar uma nova perspectiva para a educação infantil no que diz respeito às determinações legais, regulamentações e diretrizes podemos destacar o fato de que apenas 10 anos após a promulgação da Lei de Diretrizes e Bases da Educação Nacional é que foi definida uma segunda política nacional para a educação infantil brasileira: Política Nacional de Educação Infantil - Pelo Direito Das Crianças De Zero A Seis Anos À Educação (BRASIL, 2006a). A primeira política foi formulada em 1993, sendo então substituída pela a de 2006. Tal documento expressa quais são as diretrizes da Política Nacional de Educação Infantil, os objetivos, metas, estratégias e recomendações.

Também em 2006 foi publicado o documento Parâmetros Nacionais de Qualidade para a Educação Infantil, tal documento teve entre seus colaboradores a ANPEd, UNICEF, UNESCO, MIEIB. Em sua introdução o documento afirma que sua produção se deu em virtude da necessidade de se responder com uma ação efetiva aos anseios da sociedade, além de cumprir com a determinação legal do Plano Nacional de Educação, que exige a colaboração da União para atingir o objetivo de "Estabelecer parâmetros de qualidade dos serviços de Educação Infantil, como referência para a supervisão, o controle e a avaliação, e como instrumento para a adoção das medidas de melhoria da qualidade" (BRASIL, 2001, cap. II, item 19).

O objetivo deste documento seria “(...)o de estabelecer padrões de referência orientadores para o sistema educacional no que se refere à organização e funcionamento das instituições de Educação Infantil.” (BRASIL, 2006b, p. 8). Tal documento está dividido em dois volumes sendo que o primeiro traz fundamentos e aspectos relevantes para a definição de parâmetros de qualidade para a Educação Infantil, enquanto que no segundo volume são trazidas as competências dos sistemas de ensino, a caracterização das instituições de educação infantil, além de serem apresentados os parâmetros de qualidade 
para os sistemas educacionais e para as instituições de educação infantil no Brasil. (Brasil, 2006b, p. 9-10).

No ano seguinte, em 2007 verificamos a substituição do FUNDEF pelo FUNDEB. Tal mudança configura uma efetiva possibilidade de dotação orçamentária tal almejada nas décadas para a educação infantil. Podemos considerar que apesar de todas as outras políticas citadas neste tópico é apenas a partir desta mudança que efetivamente se torna previsto em lei os recursos financeiros que a educação infantil precisaria para de fato concretizar tudo o que lhe havia sido determinado em termos de qualidade e de expansão do número de vagas. Se na Lei ${ }^{\circ} 9424$ de 24 de dezembro de 1996, que dispõe sobre o Fundo de Manutenção e Desenvolvimento do Ensino Fundamental e de Valorização do Magistério (FUNDEF) a distribuição dos recursos estava condicionado às matrículas da $1^{\mathrm{a}} \mathrm{a} 8^{\mathrm{a}}$ séries do ensino fundamental, já com a Lei $n^{\circ}$ 11.494, de 20 de junho de 2007, que regulamenta o Fundo de Manutenção e Desenvolvimento da Educação Básica e de Valorização dos Profissionais da Educação (FUNDEB), revogando a Lei ${ }^{\circ}$ 9424, o seu art. 8o prevê que a distribuição de recursos dar-se-á na proporção do número de alunos matriculados nas respectivas redes de educação básica pública (BRASIL, 2007).

Além dessa ampliação que inclui as outras etapas da educação básica na distribuição dos fundos, o art. 10 dispõe sobre a distribuição proporcional dos recursos dos Fundos, destacando ainda que esta levará em conta as diferenças entre etapas, modalidades e tipos de estabelecimento de ensino da educação básica. Ainda neste artigo a legislação prevê os seguintes tipos de estabelecimento de educação infantil: creche em tempo integral; pré-escola em tempo integral; creche em tempo parcial; pré-escola em tempo parcial.

Por fim vale destacar o Programa Nacional de Reestruturação e Aquisição de Equipamentos da Rede Escolar Pública de Educação Infantil (ProInfância), apesar deste programa ter sido instituído pela Resolução $n^{0} 6$, de 24 de abril de 2007, alguns meses antecedentes da lei que institui o FUNDEB, suas repercussões tem sido muito mais evidentes no decorrer do trabalho de anos e suas repercussões atuais se fazem muito presentes. No portal do Fundo Nacional de Desenvolvimento da Educação (FNDE) existe a referência da integração do ProInfâcia a segunda etapa do Programa de Aceleração do Crescimento - PAC 2, tal ação traçou a meta de construção de mais de seis mil unidades escolares para a educação infantil (creches e pré-escolas para crianças de até cinco anos) em todo o Brasil, e para o exercício 2013, está previsto investimento em mais 1,5 mil creches/escolas de educação infantil. É certo que tais avanços apontados aqui por meio das ações previstas no ano de 2007 pelo FUNDEB e pelo ProInfâcia são notórios no que diz respeito a destinação não apenas de preocupações curriculares, teórico e metodológicas 
para a educação infantil brasileira, mas também de recursos, de metas de expansão da oferta para vias de uma efetiva democratização, assim como parâmetros de qualidade mais elaborados.

Ainda que não seja possível aqui fazer um balanço dos anos que sucederam o ano de 2007 e suas contribuições para a educação infantil brasileira, uma notícia de 29 de março de 2012 veiculada pelo Portal Brasil, do governo federal afirma que o atendimento a crianças na pré-escola cresceu em $55 \%$ em dez anos para as crianças de 4 a 5 anos, estudo afirma que, no ano 2000, 51,4\% das crianças dessa faixa etária tinha acesso à educação e que no ano de 2010 tal índice chegou a 80,1\%. Entretanto, a mesma notícia reconhece que cerca de 1 milhão de crianças ainda se encontram fora da escola.

Outro fato interessante veiculado na mesma notícia divulgada no Portal Brasil é a referência a uma emenda constitucional que fora aprovada em 2009 e que estabelece que a pré-escola seja etapa obrigatória no País, tal medida indica um passo para além da democratização, rumo à universalização. Acredito que a Emenda Constitucional n॰ 59 de novembro de 2009 seja mais um marco a ser considerado a partir do momento em que determina que até 2016 as crianças a partir dos quatro anos devem obrigatoriamente ser matriculadas na EI. Estudos como o realizado por Estela Scheinvar e Késia D'Almeida no artigo intitulado Educação infantil: direito, controle e práticas libertárias (2012) já questionam tal medida, pois, se a Constituição de 88 e LDB previam a educação infantil como opção da família e como dever do Estado, outra realidade fica estabelecida a partir dessa emenda, o que demonstra a tendência de institucionalização de crianças cada vez mais novas e da necessidade de se refletir sobre as razões para tal mudança. Para as autoras, a obrigatoriedade da educação infantil é defendida como dispositivo de inclusão, entretanto, é preciso estar atento para o fato de que a universalização do acesso à escola foi estabelecida enquanto uma conquista, enquanto que a escolarização como prática disciplinar e sua obrigatoriedade tem se dado como uma forma de controle. (SCHEINVAR; D’ALMEIDA, 2012).

\section{Considerações finais}

Tais referências a esse processo de normatização podem ser destacadas não apenas pela obrigatoriedade da matrícula de crianças de 4 anos na educação infantil, mas também pelo crescente processo de normatização que se fez presente na educação infantil desde 1996, e que modificou propostas de educação infantil e podem acabar por aprisionar tal etapa a concepção neoliberal de eficiência no ensino fundamental como motivo maior para o incentivo da escolarização cada vez mais precoce de crianças. 
Por fim, não querendo mais estender tal discussão, apesar de perceber a riqueza teórica que ainda palpita em diversos outros estudos e notícias recentes veiculadas pelo governo federal, nesta pesquisa não há o intuito em esclarecer especificamente em que momento tal reviravolta atingiu as políticas de educação infantil, mas demonstrar efeitos da nova LDB para educação infantil e de sua inclusão no FUNDEB, assim como práticas do UNICEF que durante todo esse período continuou lançando suas objetivações para a infância, ora direcionada a saúde e sobrevivência da infância, ora a condições de vida ou maus tratos, mas nunca deixando completamente esquecida a educação infantil. Demarcar aspectos de governamentalidade infantil que permeiam os discursos do UNICEF destinados a crianças de 0 a 6 anos será o compromisso epistemológico que tal pesquisa irá empreender nas fases seguintes deste estudo mediante a análise documental dos relatórios do UNICEF no período de 1996 a 2012.

\section{Referências}

BRASIL. Presidência da República. Constituição 1988: Constituição da República Federativa do Brasil: promulgada em 5 de outubro de 1988. Brasília, DF. Recuperado de $<$ http://www.planalto.gov.br/ccivil_03/constituicao/ConstituicaoCompilado.htm>

BRASIL. Lei no 8.069. Estatuto da Criança e do Adolescente. 1990

BRASIL. Lei n ${ }^{\circ}$ 9424. Dispõe sobre o Fundo de Manutenção e Desenvolvimento do Ensino Fundamental e de Valorização do Magistério. 1996.

BRASIL. Lei no 9.394: Lei de Diretrizes e Bases da Educação Nacional (LDB). 1996.

BRASIL. Ministério da Educação. Secretaria de Educação Fundamental. Referencial curricular nacional para a Educação Infantil. Brasília: MEC/SEF, 1998.

BRASIL. Ministério da Educação. Secretaria de Educação Básica. Subsídios para credenciamento e funcionamento de instituições de educação infantil. Brasília, DF: MEC, 1998. v. 1-2.

BRASIL. Ministério da Educação. Conselho Nacional de Educação. Resolução CEB n. 01, de 13 de abril de 1999: Institui as diretrizes curriculares nacionais para a educação infantil. Diário Oficial da República Federativa do Brasil, Brasília, p. 18, seção 1. 13 abr. 1999.

BRASIL. Lei $\mathbf{n}^{0}$ 11.114. Altera os arts. $6^{\circ}, 30,32$ e 87 da lei $n^{\circ} 9.394$, de 20 de dezembro de 1996, com o objetivo de tornar obrigatório o início do ensino fundamental aos seis anos de idade. 2005.

BRASIL. Ministério da Educação. Secretaria de Educação Básica. Política Nacional de Educação Infantil: pelo direito das crianças de zero a seis anos à educação. Brasília, DF: MEC, 2006. 
BRASIL. Ministério da Educação. Conselho Nacional de Educação. Parâmetros Nacionais de Qualidade para a Educação Infantil. Brasília: MEC/SEB, $2006 \mathrm{~b}$.

BRASIL. Emenda Constitucional $N^{0} 53$. Dá nova redação aos arts. $7^{\circ}, 23,30,206,208$, 211 e 212 da Constituição Federal e ao art. 60 do Ato das Disposições Constitucionais Transitórias. 2006c.

BRASIL. Lei no 11.494. Regulamenta o Fundo de Manutenção e Desenvolvimento da Educação Básica e de Valorização dos Profissionais da Educação - FUNDEB. 2007.

BRASIL. Emenda Constitucional No 59. Dá nova redação aos incisos I e VII do art. 208 da Constituição Federal, de forma a prever a obrigatoriedade do ensino de quatro a dezessete anos e ampliar a abrangência dos programas suplementares para todas as etapas da educação básica. 2009.

BRASIL. Ministério da Educação. Secretaria de Educação Básica. Diretrizes curriculares nacionais para a educação infantil /Secretaria de Educação Básica. - Brasília: MEC, SEB, 2010 .

KRAMER, S. A política do pré-escolar no Brasil - A arte do disfarce. São Paulo: Cortez, 1995.

KRAMER, S. As crianças de 0 a 6 anos nas políticas educacionais no Brasil: educação infantil e/é fundamental. 2006. Recuperado de http://www.scielo.br/pdf/es/v27n96/a09v2796. pdf Acessado em 16/03/2012

KUHLMAN JUNIOR, M. Infância e educação infantil: uma abordagem histórica. - Porto Alegre: Mediação, 1998.

LUCAS, M. A. O. F. A influência do UNICEF e da UNESCO na educação infantil brasileira contemporânea. HISTEDBR (Online), Campinas, n. 35, p. 126-140, 2009.

ROSEMBERG, F. Organizações Multilaterais, Estado e Políticas de Educação Infantil. Revista Cadernos de Pesquisa, n. 115, p. 25-63, 2002.

ROSEMBERG, F. Panorama da educação infantil brasileira contemporânea. In: Simpósio Educação Infantil: construindo o presente, Anais... . Brasília: UNESCO Brasil, 2003.

SCHEINVAR, E.; KESIA, D. Educação infantil: direito, controle e práticas libertárias. Mnemosine, v. 8, n. 2, p. 203-224, 2012.

SILVA, M. V. et al. Contradições e Ambiguidades do Currículo e das Políticas Educacionais

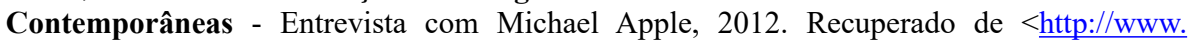
curriculosemfronteiras.org/vol12iss1articles/silva-marques-gandin.pdff>

UNICEF. Situação Mundial da Infância 2012 - Crianças em um Mundo Urbano. 2012. Recuperado de <http://www.unicef.org/brazil/pt/PT-BR_SOWC_2012.pdf>

UNICEF. Situação Mundial da Infância 2008 - Sobrevivência infantil. 2008. Recuperado de $<$ http://www.unicef.org/brazil/pt/sowc2008 br.pdfs

VEYNE, P. (1998). Como se escreve a história. Brasília: Editora da UNB. 
LEMOS, F. C. S.et al. UNICEF, infância, educação e práticas de proteção de direitos no Brasil.

Agência de fomento: $\mathrm{CNPq}$ - Bolsa produtividade.

Submissão em: 27/03/2015

Revisão em: 30/10/2017

Aceite em: 02/11/2017

Flávia Cristina Silveira Lemos é professora assistente de Psicologia Social/UFPA.

Psicóloga/UNESP, mestre em Psicologia Social/UNESP. Doutora em História/

UNESP. Bolsista de produtividade em pesquisa CNPQ2.

Endereço para correspondência: Avenida Augusto Côrrea, n. 01. PPGP-UFPA.

Bairro: Guamá. Belém/PA. CEP 66.000.

E-mail: flaviacslemos@gmail.com

Nathália Dourado Frazão Costa é mestre em Psicologia/UFPA. Psicóloga/UFPA. Graduada em Comunicação/UFPA. Mestre em Psicologia/UFPA.

E-mail: nathaliadourado@hotmail.com

Rafaele Habib Souza Aquime é doutoranda em Educação/UFPA. Psicóloga/

UNAMA. Mestre em Psicologia/UFPA.

E-mail: rafaele.habib@gmail.com

Mariane Bittencourt Batista Couto é psicóloga/UFPA. Pedagoga/UEPA. Mestranda em Psicologia/UFPA.

E-mail: maribatista@hotmail.com

Leandro Passarinho dos Reis Júnior é professor adjunto I de Psicologia da Educação/UFPA.

E-mail: 1passarinho28@gmail.com 